\title{
Using data storage tags to link otolith macro- structure in Baltic cod Gadus morhua with environmental conditions
}

\author{
K. Hüssy ${ }^{*}$ B. Nielsen, H. Mosegaard, L. Worsøe Clausen \\ National Institute of Aquatic Resources, Technical University of Denmark, Jaegersborg Alle 1, 2920 Charlottenlund, Denmark
}

\begin{abstract}
We examined otolith opacity of Baltic cod in relation to environmental conditions in order to evaluate the formation mechanisms of seasonal patterns used in age determination. Adult fish were tagged with data storage tags (DSTs) and a permanent mark was induced in the otoliths by injection of a strontium chloride solution. Based on environmental conditions experienced, fish were classified into different behavioural types: non-reproducing 'non-spawner', and 'spawner' undertaking spawning migrations. Otolith opacity, an indicator of otolith and fish somatic growth and condition, was examined in relation to these environmental drivers. Temperature was the only environmental variable with a significant effect, overlaying a strong size-related effect. The temperature effect was not uniform across behavioural types and spawning periods. Opacity showed a negative correlation with temperature as expected - but in non-spawning fish only. In spawners, the general trend was a decrease in opacity from pre- to post spawning. A significant - but positive - temperature effect was only found in the pre-spawning period. The negative effects during and following spawning were not significant. In spawners, this decoupling leads to an otolith structure with stronger contrasts and more abrupt changes, while in non-spawners, opacity changes more smoothly. The trigger for this decoupling seems to be an interaction between temperature exposure and seasonal variations in food availability and may serve as a tool to identify the occurrence and repetitiveness of spawning in Baltic cod.
\end{abstract}

KEY WORDS: Baltic cod $\cdot$ Data storage tags $\cdot$ Migrations $\cdot$ Otolith macrostructure $\cdot$ Spawning migration

Resale or republication not permitted without written consent of the publisher

\section{INTRODUCTION}

In many commercially important fish species, otoliths are used to determine fish age. Otoliths consist primarily of calcium carbonate and proteins that are continuously deposited onto the otolith surface over time and are not reabsorbed (Dunkelberger et al. 1980, Wright et al. 1991, Asano \& Mugiya 1993, Takagi \& Takahashi 1999).

Opacity is an expression of the otolith's light refraction/dispersal capacity and is a function of protein and calcium accretion rates and protein composition, where higher protein content leads to increased opacity (Mugiya \& Muramatsu 1982, Watabe et al. 1982, Seyama et al. 1991, Hüssy et al. 2004). The rates of cal- cium and protein accretion are governed by a wide range of internal and external factors, the most prominent of which are temperature (Mosegaard \& Titus 1987, Volk et al. 1990) and starvation (Neilson \& Geen 1985, Hüssy \& Mosegaard 2004), but also size and age (Morales-Nin 1986a,b, Hüssy et al. 2004). Both juvenile and adult fish develop opaque, high-contrast otoliths during periods of high growth and translucent, lowcontrast otoliths during unfavourable growth conditions (Rice et al. 1985, Titus \& Mosegaard 1991). The effect is subject to a time lag, depending particularly on fish size and water temperature (Hüssy \& Mosegaard 2004). Additionally, temperature influences the level of opacity following an inverse relationship and the effect is instantaneous. Temperature seems to be 
the environmental variable with the strongest effect on opacity (Mosegaard \& Titus 1987, Volk et al. 1990, Hüssy et al. 2004).

To date, the interpretation of the otolith microstructure of a field-caught fish has been based on knowledge gained from laboratory-reared fish. With the development of small data storage tags (DSTs) that can record the fish's physical environment, it is now possible to validate these interpretations. In the Baltic Sea, such tags have been attached to large, presumably reproductively active cod. These particular tags (StarOddi, DST-CTD) record pressure, salinity and temperature at pre-programmed time intervals. The resulting data, once the fish have been recaptured, allow a fairly precise geo-localisation of the fish throughout the tagging period (Andersen et al. 2007, Neuenfeldt et al. 2007). The Baltic cod Gadus morhua is particularly well-suited for such studies, as this species experiences strong seasonal variation in physical environment encountered, particularly during its spawning migrations. Information about the geographical and vertical distribution of cod within their natural habitat may be the key to solve one of the most pressing problems with stock assessment of Baltic cod: the determination of fish age (Reeves 2003, ICES 2006). Interpretation of the ring structure of Eastern Baltic cod otoliths is particularly difficult, as the contrast between different growth zones is very low. As a consequence thereof, annual rings are not clearly defined and ageing is subject to severe inconsistencies (Reeves 2003, ICES 2006). The use of DST records provides an opportunity to evaluate otolith microstructure patterns in an ecological context.

The Baltic Sea is a large estuary, where river runoff creates a low salinity $(\sim 7 \%$ o) surface layer typically 45 to $65 \mathrm{~m}$ thick (Matthäus \& Franck 1992, Schinke \& Matthäus 1998). Below this exists a 10 m layer, termed the upper deep-water pycnocline, which overlies the deep saline (10 to $18 \%$ ) waters of the Baltic. A seasonal thermocline is found at 30 to $40 \mathrm{~m}$ in July to September, with relatively homogeneous surface mixed layer down to the halocline during fall/winter (Kullenberg \& Jacobsen 1981, Matthäus \& Franck 1992, Møller \& Hansen 1994, Schinke \& Matthäus 1998).

Baltic cod are known for their distinct migration patterns, characterised by migrations from the coastal feeding areas and the slopes of the banks into deep areas, particularly of the Bornholm Basin and to a lesser degree the Gotland and Gdansk Deeps, for spawning (Aro 1989, Bagge et al. 1994, and references therein). In the last 2 decades, successful spawning of the eastern Baltic cod stock has largely been limited to the Bornholm Basin due to anoxic conditions in other historic spawning sites (Bagge et al. 1994, MacKenzie et al. 2000). Spawning activity occurs in the deep water layers (Tomkiewicz et al. 1998), where salinity is high enough for eggs to be buoyant (Nissling \& Vallin 1996). The spawning season of the Eastern Baltic cod stock is longer than in any other stock, but is approximately 4 to $8 \mathrm{wk}$ for the individual fish (Vallin \& Nissling 2000). Outside the spawning season, adult cod are not usually found in the deep basins (Aro 1989, Bagge et al. 1994). Thus, Baltic cod experience considerable variations in both salinity and temperature when they migrate between their near-shore feeding grounds to the spawning area in the Bornholm Basin.

In this study, we examined the influence of environmental conditions on otolith visual appearance for both reproductively active and non-spawning individuals of Baltic cod. Our major objectives were to evaluate the importance of different environmental variables in relation to seasonal zone formation in the otoliths and different signature behaviours, and to determine whether the effect of these variables may explain the age-determination problem of Baltic cod.

\section{MATERIALS AND METHODS}

Marking of fish with data storage tags and $\mathbf{S r C l}_{2}$. Cod were tagged with DSTs during April of the years 2003 to 2005 (62, 141 and 167 fish, respectively). This time was selected as it is just prior to the spawning season. Fish were captured off Nexø on the east coast of the island of Bornholm in the Baltic Sea. The geographic location of release and recapture areas are shown in Fig. 1. Individual cod $>45 \mathrm{~cm}$ total length $(\mathrm{TL})$ (average size $=55 \mathrm{~cm}$ ) were caught on a long-line at 30 to $40 \mathrm{~m}$ bottom depth and raised to the surface over $15 \mathrm{~min}$. Fish were transferred to a $0.75 \mathrm{~m}^{3}$ tank for up to $6 \mathrm{~h}$ before the swimming individuals were anaesthetised with MS-222 (dosage 1:20 000), weighed (nearest g) and measured (TL). For marking, each fish was placed in a U-shaped plastic cradle $(90 \mathrm{~cm}$ long, $15 \mathrm{~cm}$ wide and $7.5 \mathrm{~cm}$ deep), with a wet towel placed over its head and operculae. After securing the DST in the dorsal musculature below the first dorsal fin, a strontium chloride stock solution $\left(\mathrm{SrCl}_{2}, 10 \mathrm{ppt}\right)$ corresponding to $2 \mathrm{ml} \mathrm{kg}^{-1}$ body weight was injected into the body cavity. Tagging was completed within $2 \mathrm{~min}$, whereafter each fish was gently released back into the sea from the stationary vessel. The DSTs (Star-Oddi, DST-CTD) used in this study record pressure (resolution $=0.03$ bar), temperature (resolution $=0.032^{\circ} \mathrm{C}$ ) and salinity (resolution $=0.02 \mathrm{psu}$ ) in pre-programmed intervals of $15 \mathrm{~min}$ (For specific details on DST see http://www.star-oddi.com/Temperature_Recorders/ Data_Storage_Tags/conductivity_Salinity_recorder, accessed 30 March 2007). Recapture rates were on average $51 \%$ and did not differ among years. The 


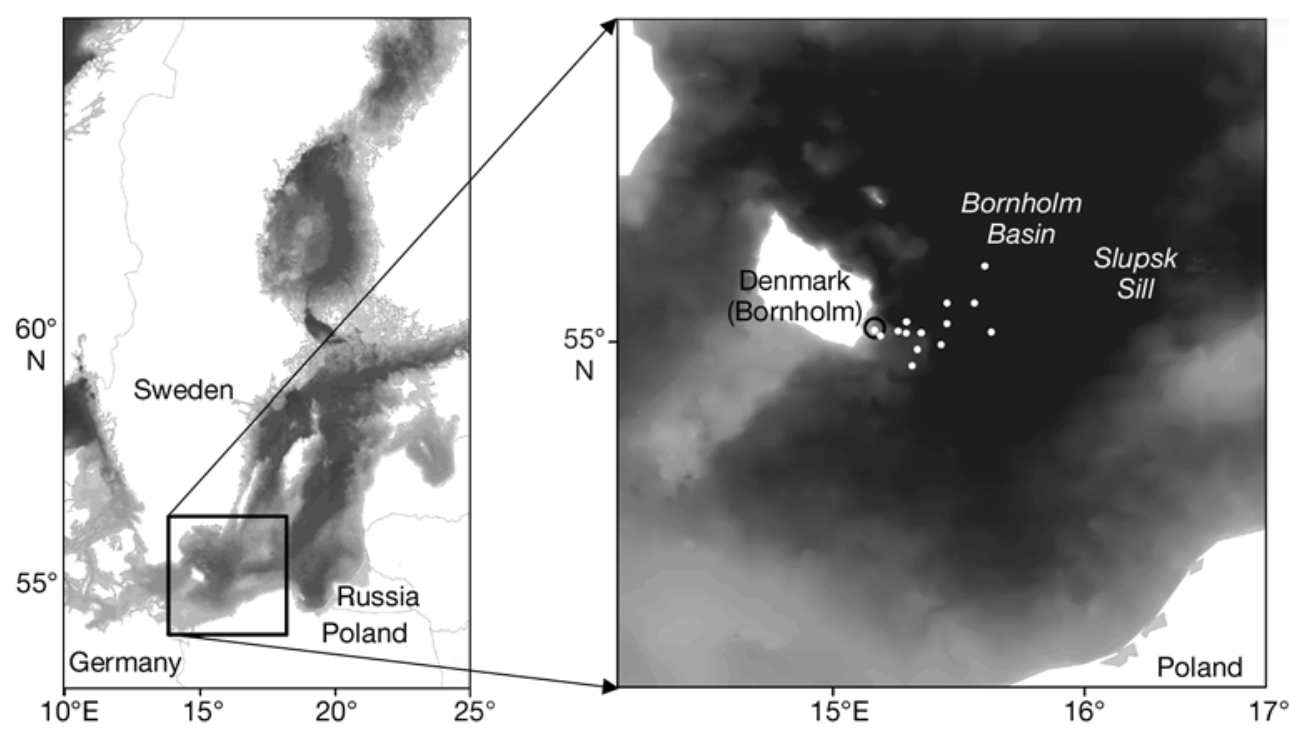

Fig. 1. Gadus morhua. Baltic Sea with release and recapture sites of cod tagged with a data storage tag (DST) off Nexø in the Eastern Baltic Sea (black circle $=$ release site, white marks = individual recapture sites). Some fish were returned without a specific recapture location other than 'east of Bornholm' (not shown) majority of recaptures were within the first $50 \mathrm{~d}$ after release. For the present study, those fish were selected which had DST records $>100 \mathrm{~d}$, which covers the entire spawning season, and with intact otoliths after preparation. This resulted in a total of 16 fish, 1 from 2003, 8 from 2004 and 7 from 2005, by coincidence all females.

Definition of signature behaviour. Activity patterns were identified based on known migration patterns of Baltic cod (Aro 1989, Bagge et al. 1994 and references therein, Tomkiewicz et al. 1998). Data from the DST records were used to allocate the tagged individuals to 2 different types of signature behaviour: spawning and non-spawning. To increase the robustness of the estimate for environmental conditions experienced, DST data were averaged to obtain a single value of temperature, salinity and depth for each day.

Spawning of Baltic cod occurs in the deep waters of the Bornholm Basin, while the feeding grounds are found in shallower areas. Spawning migrations therefore leave an easily recognisable pattern in the DST records: a sudden change in distribution towards depths below $50 \mathrm{~m}$, with a concurrent increase in salinity. In the Baltic Sea, these conditions only exist in the Bornholm Basin and fish with such DST patterns were therefore identified as spawning individuals. Geolocation of individuals with such DST records has confirmed that these individuals did in fact migrate into the Bornholm Basin (Neuenfeldt et al. 2007). Spawning fish were recaptured within 1 yr after release. Therefore, we split the DST records of each fish into 3 distinct behavioural periods, 'pre-spawning,' 'spawning' and 'post-spawning'. The threshold for the onset of spawning was set on the day when fish crossed and remained below the $50 \mathrm{~m}$ isobath for more than $7 \mathrm{~d}$. The end of spawning was defined as the day when the fish moved back into water shallower than the $50 \mathrm{~m}$ isobath.

Individuals that did not migrate into the spawning ground were defined as non-spawning. Their DST records do not show the dome-shaped signal with respect to depth and salinity characteristic of a spawning migration (Fig. 2). The DST records of these fish therefore cannot be split into different seasons.

Based on all recaptured fish DST records it was estimated that 50 to $60 \%$ of the tagged individuals were spawning, with no differences in proportion between years (S. Neuenfeldt pers. comm.). All individuals selected for this study were females, of which 10 were identified as spawning and 6 as non-spawning. A summary of their data is given in Table 1.

The migratory behaviour in relation to spawning/ non-spawning was corroborated by examination of the gonads after recapture. A sub-sample of the frozen ovarian tissue was preserved in formalin buffered with $\mathrm{NaH}_{2} \mathrm{PO}_{4}-\mathrm{H}_{2} \mathrm{O}$ and $\mathrm{Na}_{2} \mathrm{HPO}_{4}-2 \mathrm{H}_{2} \mathrm{O}$ for histological determination of maturity. The preserved ovarian tissue was embedded in paraffin using standard procedures, sectioned at $5 \mu \mathrm{m}$ and stained using hematoxylin and eosin (H\&E). The ovarian development and thus maturity of these sections was evaluated histologically based on characteristics of the larger and more advanced oocytes following the procedures by Tomkiewicz et al. (2003).

Otolith preparation. After recapture, fish TL, weight, sex and maturity were recorded. DST data were downloaded. Sagittal otoliths were removed and cleaned in Ringer solution. A segment was cut from the central transverse plane of the otolith (ISOMET 1000 Buehler), fixed on a microscope slide with thermoplastic glue (Buehler Thermoplastic Cement no. 40-8100), 

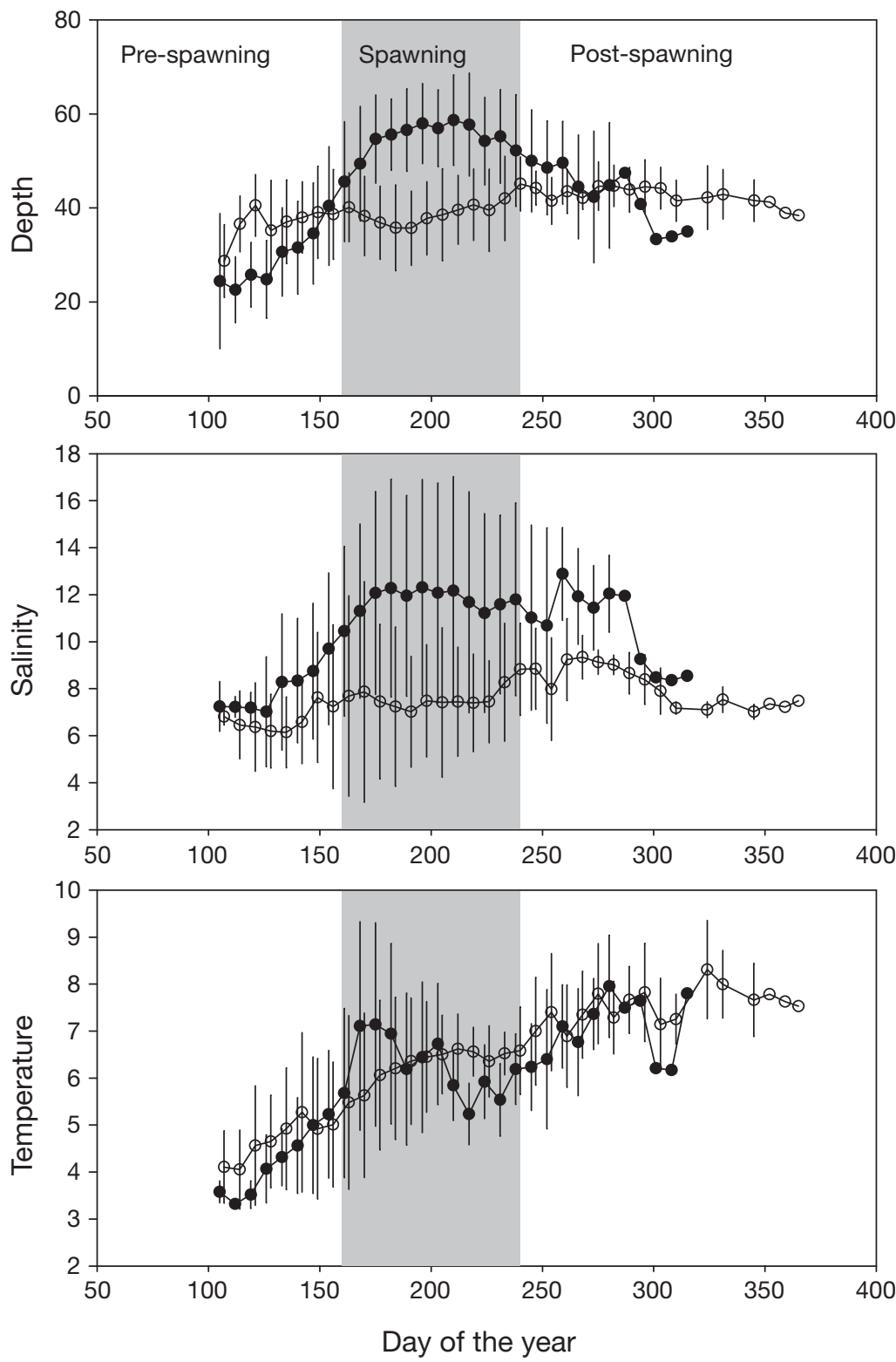

Fig. 2. Gadus morhua. Environmental conditions experienced by fish with different signature behaviours (spawners and non-spawners) (mean $\pm \mathrm{SD}$ ). Shown are the data storage tag (DST) data for temperature $\left({ }^{\circ} \mathrm{C}\right)$, salinity and depth (m) in relation to day of the year (spawners $=\mathbf{0}, \mathrm{n}=10$; non-spawners $=0, \mathrm{n}=6$; shaded area $=$ spawning period; $2 \mathrm{~d}$ were added to the non-spawners to avoid overlaying of graphs)

and ground from both sides to a thickness of approximately $200 \mu \mathrm{m}$ using abrasive paper (grit 30 to $0.3 \mu \mathrm{m}$ ) and polished with $1.0 \mu \mathrm{m}$ alumina paste. The polished surface was carbon coated for identification of the Srenriched growth band in the otolith under a scanning electron microscope (SEM) in backscatter mode. Otolith growth after marking was measured as the longest distance between the Sr-band and the otolith edge along the dorsal growth axis.
Otoliths were viewed in reflected light under a stereo microscope (Leica MZ6) and images digitised (Leica DFC320 camera and Leica IM 50 framegrabber) using a standard setup of exposure $(107.9 \mathrm{~ms}, 8 \mathrm{bits} / \mathrm{channel}$ with a frame of $1300 \times 1030$ pixels), light intensity, angle and direction of illumination. Pictures were oriented with the dorsal axis of the section placed horizontally and the centre of the otolith to the left by rotating the camera. Otolith optical characteristics were examined as a profile of grey values (profile tool of IMAGE PRO ver. 5.0) corresponding to the growth since first capture derived from the SEM analysis. Grey values range between 0 (black) and 255 (pure white), where high values correspond to high dispersion of light due to high otolith protein content (Watabe et al. 1982, Seyama et al. 1991). These grey values are referred to henceforth as opacity.

Opacity is significantly influenced by section thickness (Hüssy et al. 2004). Since not all otolith sections were exactly $200 \mu \mathrm{m}$, the opacity profiles were standardised to this thickness. Section thickness was measured using the microscope's micrometer scale. With permanent ink, 4 marks were set on the slide at equal distances and angles from the otolith. The thickness of the otolith was calculated as the difference between the average of the slide readings and the reading at the otolith surface. Opacity $(\kappa)$ of each individual pixel of the profile was standardised to $200 \mu \mathrm{m}$ :

$$
\begin{gathered}
\kappa_{\mathrm{s}}=255 \times\left\{1-\exp \left[200 / h_{\mathrm{m}} \times\right.\right. \\
\left.\left.\ln \left(\kappa_{\mathrm{m}} / 255\right)\right]\right\}
\end{gathered}
$$

where $\kappa_{\mathrm{s}}$ is standardised opacity, $h_{\mathrm{m}}$ is measured thickness, and $\kappa_{\mathrm{m}}$ is measured opacity. From these standardised opacity profiles daily average opacity was calculated. This was achieved by dividing the total number of profile pixels of each fish with the number of DSTdays, resulting in number of pixels per day. Average daily opacity $\left(\kappa_{\mathrm{a}}\right)$ was then calculated by averaging values over the resulting number of pixels along the entire profile. This procedure was chosen because the preparation and examination technique used is able to reveal seasonal patterns in growth and behav- 
Table 1. Gadus morhua. Individual fish lengths (cm), weights $(\mathrm{g})$ and condition (Fulton $K$ ) at release and recapture, in relation to year and signature behaviour. Averages for total spawners and non-spawners across all years are also given. Years represent the year the fish were tagged. BT = behaviour type, days = days of DST data, ns = non-spawner, $\mathrm{s}=$ spawner

\begin{tabular}{|c|c|c|c|c|c|c|c|}
\hline \multirow[t]{2}{*}{ BT } & \multirow[t]{2}{*}{ Days } & \multicolumn{3}{|c|}{ - Release } & \multicolumn{3}{|c|}{ - Recapture } \\
\hline & & Length & Weight & Fulton $K$ & Length & Weight & Fulton $K$ \\
\hline \multicolumn{8}{|c|}{2003} \\
\hline ns & 105 & 62 & 2089 & 0.88 & 61 & 1883 & 0.83 \\
\hline \multicolumn{8}{|c|}{2004} \\
\hline $\mathrm{s}$ & 107 & 47 & 1020 & 0.98 & 48 & 828 & 0.75 \\
\hline $\mathrm{s}$ & 162 & 54 & 1260 & 0.80 & 54 & 1101 & 0.70 \\
\hline $\mathrm{s}$ & 214 & 57 & 1640 & 0.89 & 64 & 2223 & 0.85 \\
\hline $\mathrm{s}$ & 155 & 62 & 2380 & 1.00 & 60 & 1993 & 0.92 \\
\hline ns & 154 & 54 & 1320 & 0.84 & 54 & 1122 & 0.73 \\
\hline ns & 101 & 62 & 2140 & 0.90 & 57 & 1551 & 0.86 \\
\hline ns & 350 & 69 & 2440 & 0.74 & 79 & 3659 & 0.76 \\
\hline ns & 238 & 61 & 1880 & 0.83 & 67 & 2110 & 0.72 \\
\hline \multicolumn{8}{|c|}{2005} \\
\hline $\mathrm{s}$ & 121 & 56 & 2300 & 1.31 & 58 & 1228 & 0.63 \\
\hline $\mathrm{s}$ & 133 & 50 & 1380 & 1.10 & 51 & 891 & 0.69 \\
\hline $\mathrm{s}$ & 157 & 50 & 1300 & 1.04 & 53 & 1508 & 1.04 \\
\hline $\mathrm{s}$ & 109 & 50 & 1260 & 1.01 & 50 & 739 & 0.61 \\
\hline $\mathrm{s}$ & 174 & 49 & 1040 & 0.88 & 51 & 797 & 0.60 \\
\hline $\mathrm{s}$ & 130 & 49 & 1020 & 0.87 & 50 & 1404 & 1.16 \\
\hline ns & 116 & 56 & 1560 & 0.89 & 56 & 1374 & 0.80 \\
\hline \multicolumn{8}{|c|}{ Average } \\
\hline \multicolumn{2}{|c|}{ Spawners } & 52 & 1460 & 0.99 & 54 & 1271.2 & 0.79 \\
\hline \multicolumn{2}{|c|}{$\begin{array}{l}\text { Non- } \\
\text { spawners }\end{array}$} & 61 & 1905 & 0.85 & 62 & 1950 & 0.78 \\
\hline
\end{tabular}

dure may be found at http://cran.r-project. org/doc/contrib/Fox-Companion/appendixmixed-models.pdf (last accessed 4 March 2008).

\section{RESULTS}

\section{Habitat and fish characteristics}

Habitat

The differences in habitat characteristics of the 2 behavioural groups are illustrated in Fig. 2. These 3 panels clearly show that even though there are some general characteristics associated with the different signature behaviours, there are also large variations in environmental conditions experienced within types. Minor problems were encountered toward the end of the tagging period for 3 tags (2 spawning, 1 non-spawning), where abnormal or non-existent data occurred and were discarded.

Spawning fish all move to deep water with highly variably onset of this migration, ranging from Day 130 of the year to Day 180 (mid-April to end of June). The fish migrate back to more shallow waters within Days

iour, and while it limits the conclusions that can be made based on daily observations, growth differences from one day to the next are limited (IBACS 2006, K. Hüssy pers. obs.). The standardised, averaged opacity profiles were then compared to daily averaged DST data using the statistical methods described below.

Statistical analyses. All statistical analyses were carried out using the statistical package $\mathrm{R}$ (http://wiki. r-project.org/rwiki/doku. php, last accessed 4 March 2008).

The relationship between otolith opacity and environmental data was analysed using linear mixedeffect models (LME). In addition to fixed effects these models include additional random-effect terms and are therefore appropriate when observations are made over time on the same individuals. In this case fixed effects were the environmental variables measured by the DSTs (date, temperature, density, salinity) and individuals the random effects. To evaluate whether the random intercepts and slopes were necessary, each in turn was omitted from the models. The degree of autocorrelation of within-individual errors was tested using the continuous ARIMA 1 (corCAR1) function of $\mathrm{R}$, and the optimal model was selected by contrasting all models with the original model using likelihoodratio statistics. A detailed description of this proce-
200 to 250 (mid July to mid September). All recapture locations were within the vicinity of the release site, indicating that fish return to their feeding grounds. During this migration, they experience an increase in salinity from 8 to $9 \mathrm{ppm}$ to $>12 \mathrm{ppm}$. Following release, the environmental temperature increased from $3-4^{\circ} \mathrm{C}$ to $8-10^{\circ} \mathrm{C}$. During the migration into the Basin, they experience temperatures as low as $5^{\circ} \mathrm{C}$, which increases again after migration back into shallow water.

Non-spawning fish seem to either remain relatively stationary at the same depth or move about within the depth range 20 to $45 \mathrm{~m}$. During the time with a DST, these fish experienced a gradually increasing temperature regime, from $3-4^{\circ} \mathrm{C}$ to $8-10^{\circ} \mathrm{C}$, and a fluctuating salinity ( 7 to $12 \mathrm{ppm}$ ), depending on the depth occupied.

Fish

We examined length and weight measured at release and recapture. The only significant differences between spawning and non-spawning fish were found in length $(F$-test, df =9,5, p = 0.36; Student's $t$-test, $\mathrm{df}=$ $14, \mathrm{p}<0.05)$ and condition $(F$-test, $\mathrm{df}=9,5, \mathrm{p}=0.03$; Student's $t$-test for unequal variance, $\mathrm{df}=13, \mathrm{p}<0.05$ ) 
at release and in length at recapture ( $F$-test, $\mathrm{df}=9,5$, $\mathrm{p}=0.06$; Student's $t$-test, $\mathrm{df}=14, \mathrm{p}<0.05$ ). Apparently, particularly large fish skipped spawning and were thus classified as non-spawning. The spawning activity of cod in the year of release can be reliably predicted by macroscopic indices up to the end of September (Day 280 of the year), hereafter histological examination may be necessary. The maturity state of all spawning fish ranged between maturing and spent. In the histological section of these fish, we observed artretic cells-indicators of recent spawning. The maturity of all non-spawning fish was immature or resting at recapture. In none of the histological sections of non-spawning fish, including those recaptured after the end of September, were there any signs of artretic cells, indicating that these fish had in fact skipped spawning. This suggests that migrations are undertaken by reproductively active fish, while nonreproductive fish did not migrate. Fish condition at release was significantly higher in spawning fish, possibly due to the weight of the developing gonads. At recapture, there were no differences in condition between the 2 behaviour types.

\section{Effect of marking}

To assess the possible bias induced by the stress the fish were exposed to during the DST and Sr marking, otolith opacity was averaged over the 10 pixels just prior to the Sr mark and compared with the average of the 10 pixels after the mark. No changes in opacity occurred in connection with the Sr mark $(F$-test, $\mathrm{df}=14, \mathrm{p}=0.31$; paired $t$-test, $\mathrm{df}=15, \mathrm{p}=0.85$ ).

\section{Opacity in relation to signature behaviour}

\section{Correlation of opacity with DST data for the whole profile}

Individual variability in opacity at the macroscopic scale was extensive. However, one feature common to all individuals was the decreasing opacity with time, regardless of fish size, year or behaviour (Fig. 3).

For all variables, the individual effects as well as the autocorrelation terms were highly significant (LME, groups $=16$, all $\mathrm{p}<0.001$ ). Therefore, individual intercepts and slopes and autocorrelation were kept in the model. Of the variables measured by the DSTs (date, depth, temperature and salinity), date was the only variable with a significant effect on otolith opacity (LME, groups $=16, \mathrm{r}^{2}=$ 0.83, p < 0.001) (Table 2). To evaluate the effect of a possible year effect, these residual opacity-DST data relationships were tested using tagging year as fixed effects in the LME. There were no significant differences in the coefficient between years (LME, groups = $16, \mathrm{p}>0.05)$.

To remove the effect of the size-related decrease in opacity (Fig. 3), we used time-detrended data (termed residual opacity, $\kappa_{\mathrm{r}}$ ) in our analyses. Since individual effects on the linear relationship between opacity and date were highly significant (see paragraph above) we calculated an intercept ( $\left.a_{\text {individual }}\right)$ and coefficient ( $\left.b_{\text {individual }}\right)$ of this relationship for each individual fish. Residual opacity, calculated for each pixel along the profile, is the difference between the standardised observed opacity and this average value:

$$
\kappa_{\mathrm{r}}=\kappa_{\mathrm{s}}-\kappa_{\mathrm{a}}
$$

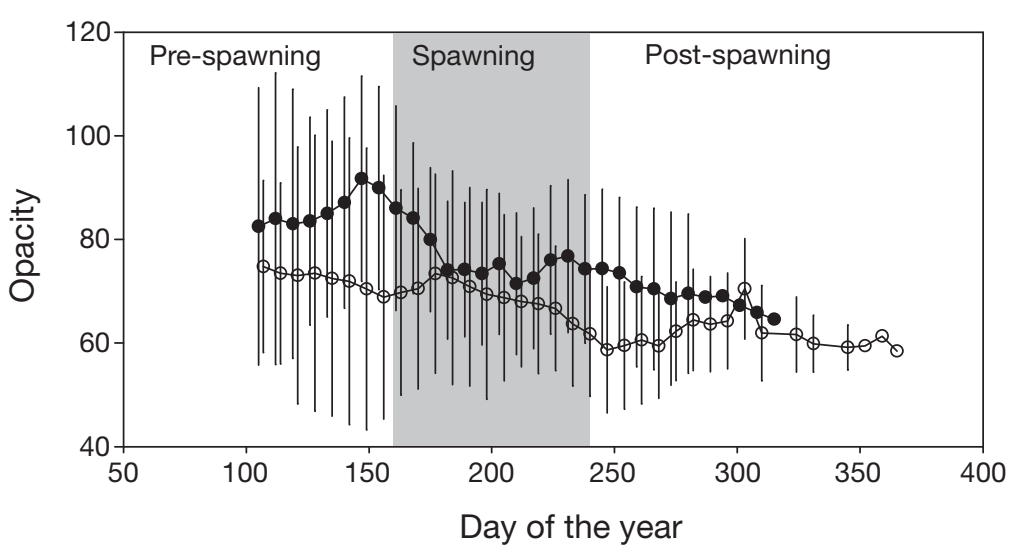

Fig. 3. Gadus morhua. Otolith opacity (Mean $\pm \mathrm{SD}$ ) corresponding to the period of data storage tag (DST) data $(\bullet=$ spawners, $\mathrm{n}=10$; $\mathrm{O}=$ non-spawners, $\mathrm{n}=6$; shaded area $=$ spawning period; 2 days were added to the non-spawners to avoid overlaying of graphs)

Table 2. Gadus morhua. Statistical details of the effect of different variables on otolith opacity over the entire profile from Sr mark to the edge of the otolith. Significance levels: ns: $\mathrm{p}>0.05,{ }^{*} \mathrm{p}<0.05,{ }^{* *} \mathrm{p}<0.01,{ }^{* * *} \mathrm{p}<0.001$

\begin{tabular}{|lrcccccc|}
\hline Variable & Intercept & Coefficient & Groups & $\mathrm{n}$ & $\mathrm{r}^{2}$ & $\mathrm{p}_{\text {int }}$ & $\mathrm{p}_{\text {coeff }}$ \\
\hline Opacity & & & & & & & \\
$\begin{array}{l}\text { Date } \\
\text { Temperature }\end{array}$ & 106.79 & -0.17 & 16 & 1257 & 0.83 & ${ }^{* * *}$ & ${ }^{* * *}$ \\
$\begin{array}{l}\text { Depth } \\
\text { Salinity }\end{array}$ & 78.22 & 0.05 & 16 & 1257 & 0.05 & ${ }^{* * *}$ & $\mathrm{~ns}$ \\
Residual opacity & 93.02 & -0.26 & 16 & 1257 & 0.13 & ${ }^{* * *}$ & $\mathrm{~ns}$ \\
Temperature & 1.349 & -0.227 & 16 & 1257 & 0.10 & $*^{* * *}$ & $* * *$ \\
$\begin{array}{l}\text { Depth } \\
\text { Salinity }\end{array}$ & 0.285 & -0.079 & 16 & 1257 & 0.001 & $\mathrm{~ns}$ & $\mathrm{~ns}$ \\
& 0.182 & -0.018 & 16 & 1257 & $4.0 \mathrm{e}^{-04}$ & $\mathrm{~ns}$ & $\mathrm{~ns}$ \\
\hline
\end{tabular}


where $\kappa_{\mathrm{a}}=a_{\text {individual }}-b_{\text {individual }} \times$ date. This procedure removes the date effect from the data and allows testing of the effect of the environmental variables on the remaining variability of otolith opacity. The effect of the environmental variables temperature, depth and salinity on residual opacity was then examined using the same type of LME analysis as before.

This approach revealed that temperature is the only DST-measured variable correlated with otolith opacity, explaining $10 \%$ of residual variation (Table 2 ). Individual effects were still highly significant and kept in the model (LME, groups $=16$, all $p<0.001$ ), but autocorrelation was not (LME, groups $=16$, all $p>0.05$ ). Therefore, we concentrate on the effect of temperature in the following, where all analyses are based on this residual opacity and linear mixed-effects analysis.

\section{Difference between behaviour types}

First we tested the hypothesis that there are no differences in the otolith residual opacity-temperature relationship between spawning and non-spawning individuals. The residual opacity-temperature data were analysed using behaviour type (spawning/non-spawning) as fixed effects in the LME. There were significant differences in the coefficient of the relationship between non-spawning and spawning individuals (LME, groups $=16, p<0.001$ ), where temperature explains $23 \%$ of residual opacity in non-spawning but only $9 \%$ in spawning fish (Table 3).

\section{Difference between behaviour seasons of spawners}

Does the difference in otolith residual opacity response to temperature between the 2 behaviour types originate from certain behavioural periods of spawn-

Table 3. Gadus morhua. Statistical details of residual opacity-temperature relationship for different behaviour types (non-spawner/spawner) and behaviour seasons within spawners (whole profile: The entire profile from the Sr mark to the edge without segregation into behaviour seasons). Significance levels: ns: $p>0.05$,

$$
{ }^{*} \mathrm{p}<0.05,{ }^{* *} \mathrm{p}<0.01,{ }^{* * *} \mathrm{p}<0.001
$$

\begin{tabular}{|lcccccccc|}
\hline Period & Intercept & Coefficient & Groups & $\mathrm{n}$ & $\mathrm{r}^{2}$ & $\mathrm{p}_{\text {int }}$ & $\mathrm{p}_{\text {coeff }}$ \\
\hline Non-spawner & & & & & & & & \\
Whole profile & 4.330 & -0.813 & 6 & 468 & 0.23 & $* * *$ & $* * *$ \\
Spawner & & & & & & & \\
Whole profile & -1.433 & 0.229 & 10 & 787 & 0.09 & ${ }^{* *}$ & $*^{* *}$ \\
Pre-spawning & -2.626 & 0.513 & 10 & 411 & 0.141 & ${ }^{* * *}$ & ${ }^{* * *}$ \\
Spawning & 0.077 & -0.072 & 10 & 274 & $9.0 \mathrm{e}^{-04}$ & $\mathrm{~ns}$ & $\mathrm{~ns}$ \\
Post-spawning & 1.599 & -0.262 & 10 & 98 & 0.007 & $\mathrm{~ns}$ & $\mathrm{~ns}$ \\
\hline
\end{tabular}

ers? A prerequisite would be seasonal differences within spawners, therefore, we tested the hypothesis that the residual opacity-temperature relationship in spawning fish is the same prior to, during and following spawning. Using behaviour period (pre-spawning/ spawning/post-spawning) within migrating individuals as fixed effects, we found significant effects on both the coefficient and the intercept of the relationship (LME, groups $=10, p<0.001)$. This effect was positive during the pre-spawning period and negative during the spawning and post-spawning periods but only significant during the pre-spawning period, when $14 \%$ of the variability was explained by temperature (Table 3). This implies that temperature only has an impact on otolith opacity during the pre-spawning period, but that other factors interfere during the other seasons.

\section{Difference between non-spawners and behaviour seasons of spawners}

Spawning appears to depend on growth and condition, where spawning fish are in good condition prior to spawning and in poor condition after spawning (Kraus et al. 2008). Fish that skip spawning are often in bad condition (Rideout et al. 2000). We tested the hypothesis that there are significant differences in the temperature response of residual otolith opacity between the different seasons of spawning fish compared to the response of non-spawners. Using behaviour type as fixed effects, the temperature effect was significantly different between non-spawning and spawning fish during the pre-spawning and spawning period (LME, groups $=16, \mathrm{p}<0.01$ ), but during the post-spawning period the spawning and non-spawning fish were similar in their opacity response to temperature $(\mathrm{LME}$, groups $=16, \mathrm{p}>0.05)$. A boxplot of residual opacity illustrates the development of otolith opacity within the different behavioural seasons of spawners (Fig. 4). This plot shows that a decrease in opacity occurs between the pre-spawning period and the spawning season. Otolith opacity decreases even more following spawning, indicating that the energy available for growth is decreasing over the seasons. Residual opacity of non-spawning fish, averaged over the entire profile, equals 0 and is therefore not included in the figure. The opacity response of spawning fish is only not significantly different from that of non-spawning fish in the postspawning season, indicating that 


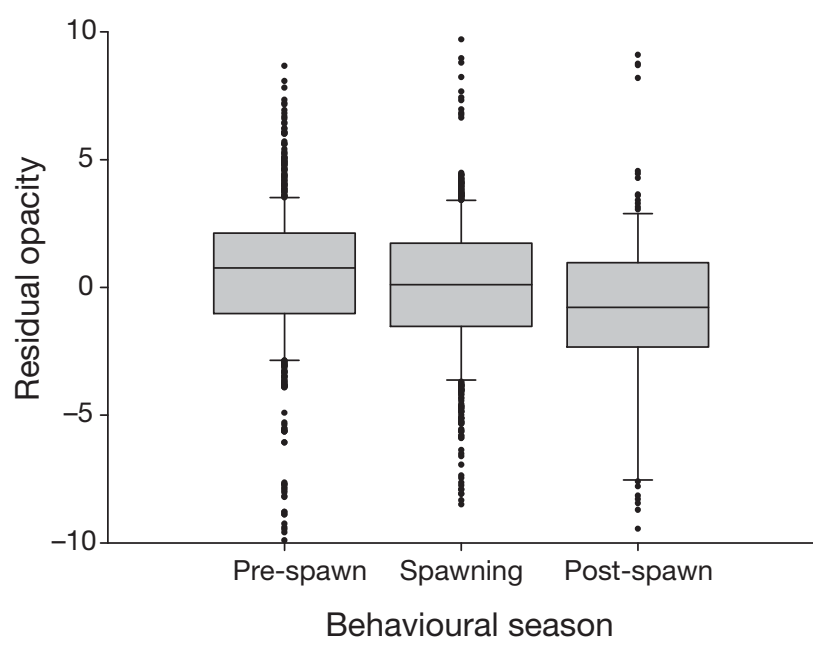

Fig. 4. Gadus morhua. Residual opacity in relation to different behaviour seasons of spawning cod and for the entire tagging period of non-spawning individuals (horizontal lines indicate median and lower/upperquartiles, whiskers = interquartile range, dots = observations outside range)

these fish may be in similar physiological state. This underlines the conclusion that otolith opacity in wild fish is not only temperature related, but that other factors (not accounted for by the DST data) play an important role as well.

\section{DISCUSSION}

This study has demonstrated that otolith opacity is not a simple function of a single parameter in wild Baltic cod - on the contrary, a range of factors appear to act in combination to create the opacity patterns observed. This study focused on evaluating seasonal patterns, associated with different types of signature behaviour.

Signature behaviour was defined as either spawning or non-spawning based on DST records of individuals in relation to known migration patterns. Since this technique is relatively new in relation to studies on cod, literature on the applicability of DSTs is sparse. In the North Sea/Skagerrak area, DSTs have proved useful for resolving daily and seasonal distribution patterns (Hobson et al. 2007), discrimination between resident and migrating stock components (Neat et al. 2006, Wright et al. 2006a, Svedäng et al. 2007), spawning site fidelity and natal homing (Wright et al. 2006b, Svedäng et al. 2007). Compared to the North Sea, definition of the migration patterns of Baltic cod is simple, owing to the unique hydrography and the well-defined spawning area.

Surprisingly, most non-spawning fish were large fish, which one would expect to be reproductively active. Recapture data confirmed that these fish were not participating in spawning (immature or resting gonads). At release their condition was poorer than that of spawners. This is not a conclusive result, since the better condition in spawners was possibly due to the weight of the developing gonads. However, the lower average otolith opacity in non-spawners supports this assumption. At recapture, the condition was equally poor in the 2 behaviour types. If non-spawning fish had lost weight in the form of eggs, their condition would have been considerably worse. In other cod stocks, skipped spawning seems to be linked to failed production of viable eggs and subsequent atresia as a result of low nutritional condition (Rideout et al. 2000). In the Baltic, skipped spawning, degeneration of ovaries and atresia, the mass resorption of vitellogenic oocytes, are known to increase with fish size (Tomkiewicz et al. 2003). Seen in the light of these results, the skipped spawning of the larger fish from our tagging experiment may have been induced by poor condition. However, due to the lack of more reliable measures of condition, other mechanisms may also be responsible for the skipped spawning.

In other Northeast Atlantic ecosystems, cod experience more or less pronounced variations in temperature in synchrony with the seasonal feeding patterns, which lead to distinct opacity patterns in the otolith macrostructure (Weidman \& Millner 2000, Høie \& Folkvord 2006). But this is not the case in Baltic cod. The strongest signal in the otolith opacity profiles of all individuals from the present study was date. Date also represents age and size of the fish/otolith, and a negative relationship between opacity and otolith size is an inherent trait of the otolith macrostructure. Thus, the strong time signal seems to be the result of a change in otolith protein composition related to size. With increasing fish size/age, the proportion of water-soluble protein is known to decrease (Morales-Nin 1986b, Hüssy et al. 2004). This implies that opacity on a macrostructural scale is regulated by some intrinsic mechanism, resulting in decreasing opacity from centre to edge. To remove the effect of this size-related decrease in opacity, we used time-detrended data in this study.

As expected, temperature influences otolith opacity in wild Baltic cod. But the effect is not uniform, neither across individuals nor throughout the season. In nonspawning fish, temperature explains $23 \%$ of residual opacity and is negatively correlated with temperature. This is in line with the response in both laboratoryreared juveniles (Hüssy \& Mosegaard 2004) and adults (Høie \& Folkvord 2006). In migrating fish however, a somewhat different picture emerges. The temperature effect is strongest in the pre-spawning period, explaining $14 \%$ of the variation, but the effect is positive and 
thereby opposite to what may be expected (Hüssy et al. 2004, Høie \& Folkvord 2006). During and following spawning, residual opacity is negatively correlated with temperature as expected, but the effect is not significant for both periods. These results show that other factors than just temperature need to be examined in order to explain the lack of a strong seasonal zone formation. Since food consumption is the other prominent mechanism affecting protein accretion in otoliths (Neilson \& Geen 1985, Hüssy \& Mosegaard 2004), the feeding dynamics of Baltic cod may provide an explanation for these opposing opacity-temperature patterns.

Food consumption of adult, reproductively active Baltic cod shows seasonal patterns both with respect to prey species and quantity of food consumed (Zalachowski et al. 1975, Bagge 1981, Bagge \& Bay 1987, Bagge et al. 1994, Maczassek 2006). In the Bornholm Basin, feeding intensity increases from November/ December to a peak in May, followed by a decrease to a seasonal low during the main spawning season in summer (Bagge 1981, Maczassek 2006). The type of prey selected also varies over the year, from clupeids in spring to invertebrates later in the year (Zalachowski et al. 1975, Bagge 1981, Bagge \& Bay 1987, Bagge et al. 1994, Maczassek 2006). This seasonal pattern in prey selection and ingestion rate implies that cod optimise their energy consumption prior to spawning, both with respect to quantity and quality. During spawning, food consumption is very limited (less than 20 to $25 \%$ of maximum consumption) and of lower energetic content (Bagge 1981, Maczassek 2006). Following spawning, cod move into shallower water, and increase their consumption and the ratio of energetically more profitable prey (Bagge 1981, Maczassek 2006).

In the pre-spawning season, the positive relationship between temperature and otolith opacity therefore is an artefact which seems to be the result of a concurrently increasing food consumption, where fish are optimising their energetic reserves in order to prepare for the spawning season. During and following spawning, otolith opacity was negatively related to temperature, as expected from the laboratory experiments on juveniles. But why is this effect not significant, as in non-spawning fish? For spawning, Baltic cod move to the deepest parts of the Bornholm Basin, where summer temperatures are lower than in the surface layer (Bagge et al. 1994, this study). The combined effects of increased energy demand due to spawning and the concurrent decrease in energy consumption should promote a decrease in residual opacity. But due to this drop in environmental temperature, the decrease in residual opacity is smaller than expected and the relationship with temperature not strong. When returning to the feeding grounds, fish experience increasing temperatures resulting, as expected, in lower opacity. But the opacity-temperature relation is still statistically insignificant and only slightly stronger than during spawning. This may only be achieved by increasing food consumption, which corresponds well with the known seasonality in food ingestion described above. Thus, the lack of a consistent, significant temperature effect in migrating cod may be related to the environmental conditions prevailing in the Baltic Sea in relation to the spawning migrations and the seasonal cycle in food consumption.

This study has underlined the use of DSTs in resolving features of fish biology and behaviour in relation to the growth characteristics recorded in the otolith macrostructure. Our results present evidence that in the wild, otolith opacity is a complex function of a series of intrinsic and exogenous mechanisms. Factors such as fish age, condition, behaviour and feeding cycle are able to override and alter the temperature effect. In the Baltic Sea, the unique combinations of interacting seasonal variations in feeding intensity and temperature experience result in an optically rather uniform otolith structure with limited contrast - particularly in migrating fish. This low-contrast otolith structure with a lack of a strong seasonal variation in opacity may therefore be regarded as the most prominent cause for the age determination problems experienced. This study thus highlights that processes explaining otolith growth features in the controlled laboratory environment may not be directly applicable to natural habitats but must be evaluated in combination with other factors as well.

Acknowledgements. This research was funded by the EU project CODYSSEY (QLRT-2001-00813). We gratefully acknowledge the help of skipper C. Holm, crew and scientific staff onboard the commercial vessel 'Britta' for the tagging of fish. This study would not have been possible without the help of fishermen operating within the Baltic Sea, who returned tags and fish data to us. We are grateful for Dr. J. Tomkjewicz's expertise and assistance in the histological evaluation of the gonads. We also thank GEUS for providing the facilities for SEM analysis of the otoliths, K. Geitner for providing the GIS map and 3 anonymous reviewers for their valuable comments on an early draft of the manuscript.

\section{LITERATURE CITED}

Andersen KH, Nielsen A, Thygesen UH, Hinrichsen $\mathrm{HH}$, Neuenfeldt S (2007) Using the particle filter to geolocate Baltic cod with special emphasis on determining uncertainty. Can J Fish Aquat Sci 64:618-627

Aro E (1989) A review of fish migration patterns in the Baltic. Rapp P-V Reun Cons Int Explor Mer 190:72-96

Asano M, Mugiya Y (1993) Biochemical and calcium-binding properties of water-soluble proteins isolated from otoliths of the tilapia, Orechromis niloticus. Comp Biochem Physiol B 104:201-205 
Bagge O (1981) The yearly consumption of cod in the Baltic and the Kattegat as estimated from stomach content. ICES CM $1981 / \mathrm{J}: 27$

Bagge O, Bay J (1987) Periodicity of feeding in Baltic cod. ICES CM 1987/J:08

Bagge O, Thurow F, Steffensen E, Bay J (1994) The Baltic cod. Dana 10:1-28

Dunkelberger DG, Dean JM, Watabe N (1980) The ultrastructure of the otolithic membrane and otolith in the juvenile mummichog, Fundulus heteroclitus. J Morphol 163: 367-377

Hobson VJ, Righton D, Metcalfe JD, Hays GC (2007) Vertical movements of North Sea cod. Mar Ecol Prog Ser 347: $101-110$

> Høie H, Folkvord A (2006) Estimating the timing of growth rings in Atlantic cod otoliths using stable oxygen isotopes. J Fish Biol 68:826-837

Hüssy K, Mosegaard H (2004) Cod (Gadus morhua L.) growth and otolith accretion characteristics, examined in a bioenergetics context. Can J Fish Aquat Sci 61:1021-1031

Hüssy K, Mosegaard H, Jessen F (2004) Effect of age and temperature on amino acid composition and the content of different protein types of juvenile Atlantic cod (Gadus morhua) otoliths. Can J Fish Aquat Sci 61:1012-1020

IBACS (2006) Integrated approach to the biological basis of age estimation in commercially important fish species. Final report of the project: QQLRT-2001-01610

ICES (2006) Report of the study group on ageing issues of Baltic cod (SGABC). ICES CM 2006/BCC:08

Kraus G, Tomkiewicz J, Diekmann R, Köster FW (2008) Seasonal prevalence and intensity of follicular atresia in Baltic cod Gadus morhua L. J Fish Biol 72:831-847

Kullenberg G, Jacobsen TS (1981) The Baltic Sea: an outline of its physical oceanography. Mar Pollut Bull 12:183-186

MacKenzie BR, Hinrichsen HH, Plikshs M, Wieland K, Zezera AS (2000) Quantifying environmental heterogeneity: habitat size necessary for successful development of cod Gadus morhua eggs in the Baltic Sea. Mar Ecol Prog Ser 193:143-156

Maczassek K (2006) Nahrungsökologie des Dorsches (Gadus morhua L.) in der zentralen Ostsee. MSc thesis, ChristianAlbrechts-Universität, Kiel

> Matthäus W, Franck H (1992) Characteristics of major Baltic inflows - a statistical analysis. Cont Shelf Res 12:1375-1400

Møller JS, Hansen IS (1994) Hydrographic processes and changes in the Baltic Sea. Dana 10:87-104

Morales-Nin B (1986a) Chemical composition of the otoliths of the sea bass (Dicentrarchus labrax Linnaeus, 1758) (pisces, Serranidae). Cybium 10:115-120

Morales-Nin B (1986b) Structure and composition of otoliths of Cape hake Merluccius capensis. S Afr J Mar Sci 4:3-10

Mosegaard H, Titus R (1987) Daily growth rates of otoliths in yolk sac fry of two salmonid species at five different temperatures. In: Kallander SO, Farnholm B (eds) Proc V Congr Europ Ichthyol, Swedish Museum of Natural History, Stockholm

Mugiya Y, Muramatsu J (1982) Time-marking methods for scanning electron microscopy in goldfish otoliths. Bull Japan Soc Scient Fish 48:1225-1232

Neat FC, Wright PS, Zuur AF, Gibb IM and others (2006) Residency and depth movements of a coastal group of Atlantic cod (Gadus morhua L.). Mar Biol 148:643-654

Neilson JD, Geen GH (1985) Effects of feeding regimes and diel temperature cycles on otolith increment formation in juvenile chinook salmon, Oncorhynchus tshawytscha. Fish Bull (Wash DC) 83:91-101

Neuenfeldt S, Hinrichsen $\mathrm{HH}$, Nielsen A, Andersen $\mathrm{KH}$ (2007) Reconstructing migrations of individual cod (Gadus morhua L.) in the Baltic Sea by using electronic data stor- age tags. Fish Oceanogr 16:526-535

Nissling A, Vallin L (1996) The ability of Baltic cod eggs to maintain neutral buoyancy and their opportunity for survival in fluctuating conditions in the Baltic sea. J Fish Biol 48:217-227

Reeves SA (2003) A simulation study of the implications of age-reading errors for stock assessment and management advice. ICES J Mar Sci 60:314-328

Rice JA, Crowder LB, Binkowski FP (1985) Evaluating otolith analysis for bloater Coregonus hoyi: Do otoliths ring true? Trans Am Fish Soc 114:532-539

> Rideout RM, Burton MPM, Rose GA (2000) Observations on mass atresia and skipped spawning in Northern Atlantic cod, from Smith Sound, Newfoundland. J Fish Biol 57: $1429-1440$

> Schinke H, Matthäus W (1998) On the causes of major Baltic inflows - an analysis of long time series. Cont Shelf Res 18:67-97

Seyama H, Edmonds JS, Moran MJ, Shibata Y, Soma M, Morita $\mathrm{M}$ (1991) Periodicity in fish otolith $\mathrm{Sr}, \mathrm{Na}$, and $\mathrm{K}$ corresponds with visual banding. Experientia 47:1193-1196

Svedäng H, Righton D, Jonsson P (2007) Migratory behaviour of Atlantic cod Gadus morhua: natal homing is the prime stock-separating mechanism. Mar Ecol Prog Ser 345:1-12

> Takagi Y, Takahashi A (1999) Characterisation of otolith soluble-matrix producing cells in the saccular epithelium of Rainbow trout (Oncorhynchus mykiss) inner ear. Anat Rec 254:322-329

> Titus RG, Mosegaard H (1991) Selection for growth potential among migratory brown trout (Salmo trutta) fry competing for territories: Evidence from otoliths. Can J Fish Aquat Sci 48:19-27

Tomkiewicz J, Lehmann KM, St John MA (1998) Oceanographic influences on the distribution of Baltic cod, Gadus morhua, during spawning in the Bornholm Basin of the Baltic Sea. Fish Oceanogr 7:48-62

> Tomkiewicz J, Tybjerg L, Jespersen A (2003) Micro- and macroscopic characteristics to stage gonadal maturation of female Baltic cod. J Fish Biol 62:253-275

Vallin L, Nissling A (2000) Maternal effects on egg size and egg buoyancy of Baltic cod, Gadus morhua: Implications for stock structure effects on recruitment. Fish Res 49:21-37

Volk EC, Schroder SL, Fresh KL (1990) Inducement of unique otolith banding patterns as a practical means to mass-mark juvenile Pacific salmon. Am Fish Soc Symp 7:203-215

> Watabe N, Tanaka K, Yamada J, Dean JM (1982) Scanning electron microscope observations of the organic matrix in the otolith of the teleost fish Fundulus heteroclitus (Linnaeus) and Tilapia nilotica (Linnaeus). J Exp Mar Biol Ecol 58:127-134

Weidman CR, Millner R (2000) High-resolution stable isotope records from North Atlantic cod. Fish Res 46:327-342

> Wright PJ, Rowe D, Thorpe JE (1991) Daily growth increments in the otoliths of Atlantic salmon parr, Salmo salar L., and the influence of environmental factors on their periodicity. J Fish Biol 39:103-113

> Wright PJ, Galley E, Gibb IM, Neat FC (2006a) Fidelity of adult cod to spawning grounds in Scottish waters. Fish Res 77:148-158

- Wright PJ, Neat FC, Gibb FM, Gibb IM, Thordarson H (2006b) Evidence for metapopulation structuring in cod from the west of Scotland and North Sea. J Fish Biol 69(Suppl C):181-199

Zalachowski W, Szypula J, Krzykawski S, Krzykawska I (1975) Feeding of some commercial fishes in the southern region of the Baltic Sea - in 1971 and 1972. Pol Arch Hydrobiol 22:429-448

Submitted: April 3, 2008; Accepted: December 3, 2008

Proofs received from author(s): February 23, 2009 